\title{
Trials of Zika vaccine are set to begin in North America
}

\author{
Owen Dyer
}

Montreal

The first potential vaccine against the Zika virus to be approved for testing in humans is set to begin phase I clinical trials in the United States.

The vaccine's maker, Inovio, of Pennsylvania, is currently completing the paperwork to begin recruitment of 40 volunteers to participate in Philadelphia, Miami, and an undisclosed site in Canada.

The first vaccinations are expected within a few weeks, said Inovio's president, Joseph Kim, and the first results by the year's end. In animal trials the experimental vaccine, known as GLS-5700, elicited an immune response in mice, rabbits, and monkeys.

Other collaborators in the project include the University of Pennsylvania, the biomedical Wistar Institute in Philadelphia, and GeneOne Life Science, of South Korea.

The proposed Zika vaccine is a DNA vaccine, considered a third generation vaccine. First generation vaccines rely on killed, live, or attenuated whole organisms, and second generation vaccines use subunits of the pathogen such as recombinant protein components.

The GLS-5700 vaccine consists of DNA injected directly under the skin. The injection site is then stimulated with a short electrical pulse to force the DNA into cells in a process called electroporation. These host cells then produce the pathogen's proteins and display them on their surfaces, where the immune system recognizes them as foreign and begins mounting a response.

As yet, most approved DNA vaccines are in the field of veterinary medicine, but DNA vaccines have been approved and used to prevent Japanese encephalitis.

At least 15 projects are under way to try to create a Zika vaccine. One such effort, involving collaboration between Imperial College London and the Institut Pasteur in Paris, has been examining the close relation between Zika and dengue viruses. These findings indicate that a single universal vaccine could potentially protect against both diseases simultaneously. ${ }^{1}$
This research also suggested, however, that some antibodies normally generated by dengue infection could bind to Zika virus, but instead of neutralizing it they promoted antibody dependent enhancement of Zika infection, making the disease more virulent rather than less. ${ }^{2}$ This might help to explain why Zika has struck particularly hard in areas where dengue is endemic, such as northern Brazil. It also raises the danger that vaccination against dengue might increase susceptibility to Zika.

Research to be presented this week at the Teratology Society's annual conference in San Antonio, Texas, will describe a host of symptoms seen after birth in babies of Zika infected mothers who had been deemed healthy at birth. These included frequent joint problems, vision impairment, seizures, and delays in developmental milestones, such as sitting up unaided.

This follows a Colombian study reported last week in the New England Journal of Medicine that found that Zika infection in the third trimester of pregnancy was unlikely to cause apparent birth abnormalities. ${ }^{3}$ The same study suggested that Zika infection could still have an effect on the fetus when the mother felt no symptoms, however. Most of the women enrolled in that study are still pregnant, and results are awaited to measure the effects of first trimester infection, known to be severe, and the poorly understood implications of second trimester infection.

Sixty countries on four continents have now reported cases of Zika. On Friday Indonesia said that an Australian foreign ministry travel advisory, which warned pregnant women to reconsider travel plans to Indonesia, was overstating the danger. There has been only one confirmed Zika case and no evidence of endemic local transmission in Indonesia, said the country's embassy in Canberra.

Barba-Spaeth G, Dejnirattisai W, Rouvinski A, et al. Structural basis of potent Zika-dengue virus antibody cross-neutralization. Nature 2016. doi:10.1038/nature18938. pmid:27338953. 2 Dejnirattisai W, Supasa P, Wongwiwat W, et al. Dengue virus sero-cross-reactivity drives antibody-dependent enhancement of infection with zika virus. Nat Immuno/ 2016. doi:10. 1038/ni.3515. pmid:27339099.

Pacheco O, Beltrán M, Nelson CA, et al Zika virus disease in Colombia: preliminary report. N Engl J Med2016, doi:10.1056/NEJMoa1604037.

Published by the BMJ Publishing Group Limited. For permission to use (where not already granted under a licence) please go to http://group.bmj.com/group/rights-licensing/ permissions 